\title{
Just noticeable difference in olfaction: a discrimi- native tool between healthy elderly and patients with cognitive disorders associated with dementia*
}

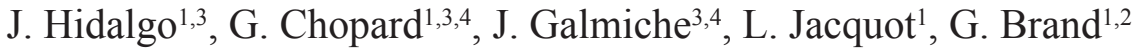 \\ 1 Neuroscience Lab, Université de Franche-Comte, Besançon, France \\ 2 Centre des Sciences du Goût et de l'Alimentation (CSGA) Dijon, France \\ 3 Centre Mémoire de Ressources et de Recherches (CMRR), Department of Neurology, \\ University Hospital, Besançon, France \\ 4 Rapidnat-Fr, Besançon, France
}

SUMMARY Olfactory dysfunction appears to be one of the earliest signs of several age-related neurodegenerative disorders, including Alzheimer's disease (AD) or Parkinson's disease (PD). To rate performance and olfactory deficits in patients with cognitive disorders, various olfactory tasks have been used such as odor detection, discrimination, recognition memory, identification and naming but no study has been focused on just noticeable difference (JND), a sensitive tool of detection. The aim of this study was to investigate and compare variations in JNDs in healthy elderly and in patients with cognitive disorders associated with dementia. The results showed significantly higher olfactory JNDs in a population with cognitive disorders associated with dementia - i.e. a lower olfactory detection performance - compared to a control population paired in age, gender and education level. Additionally, the findings of the present study showed strong correlations between cognitive performances and JND scores in the control population contrary to the patient population. These findings are discussed in relation to the relevance of using olfactory JNDs in the diagnosis of dementias.

Key words: just noticeable difference, olfactory sensitivity, dementia, Alzheimer's disease, cognitive disorders

\section{INTRODUCTION}

Treatment of olfactory information involves "peripheral" and "central" levels, which determine the global olfactory performance. The "peripheral" level corresponding to the olfactory epithelium is implied in the olfactory sensibility estimated by the measure of the detection threshold (the lowest concentration that a subject can detect) or the just noticeable difference (JND or differential threshold), the smallest difference that a subject can detect between two olfactory stimulations. The "central" level refers to a higher degree of treatment (localized on different regions of the brain) and involves more complex cognitive components such as the ability to differentiate the quality of odorants (discrimination), to recognize odor targets previously smelt (memory), or to give the name of an odorant in a list of words (identification). During ageing, degenerative changes occur in neuroreceptors in the nasal cavity ${ }^{(1)}$, in neurons of the olfactory bulb (2) as well as in cerebral regions such as thalamus, hypothalamus and hippocampus ${ }^{(3)}$. The neurotransmitter pathways can also be affected ${ }^{(4)}$. All these physiological changes of the olfactory structures occurring at both "peripheral" and "central" levels are characterized by a decrease of the olfactory sensitivity (i.e. a gradual increase of the detection threshold) ${ }^{(5-7)}$ and a decrease of the discrimination, memory and identification abilities ${ }^{(7-12)}$. Several studies have reported the decrease of the ability to smell as common in older age and as an early sign of age-related neurodegenerative disorders, including Alzheimer's disease (AD) ${ }^{(13-15)}$ and Dementia with Lewy bodies (DLB) ${ }^{(16)}$. In these pathologies, the olfactory dysfunctions seem to increase with the severity of dementia ${ }^{(16)}$. Specifically, the histopathological lesions in $\mathrm{AD}$ such as senile plaques and neurofibrillary tangles in the olfactory structures, i.e. olfactory bulb ${ }^{(17,18)}$, pyriform cortex ${ }^{(19)}$ and entorhinal cortex ${ }^{(18)}$, are known to lead to a decrease in recognition memory, odor identification and discrimination at moderate stage of disease. Deficits in olfactory detection were also described at earlier stage of AD ${ }^{(21,21)}$. Similar impairments have been reported in $\mathrm{PD}$, before the apparition of the resting tremor ${ }^{(22)}$. In the DLB, lesions observed in anterior olfactory nucleus and in amygdala are responsible for a more severe deficit of olfactory sensitivity than in $\mathrm{AD}{ }^{(16,23)}$. Thus, although 
research on various types of dementia suggest that discrimination, memory and identification olfactory abilities decrease, the possible effects on detection capacities are discussed (24-26). However, the published works have used the absolute detection thresholds preferentially to the differential threshold. In sensory perception, the differential threshold, also called just noticeable difference (JND), is defined by the level at which an increase in a detected stimulus can be perceived or the smallest change in stimulation that a subject can detect. JND might be a more sensitive measure for assessing the quality of olfactory perception in different manners such as comparative assessment between single molecule and mixtures ${ }^{(27)}$, clinical test ${ }^{(28)}$ or damages to the olfactory system ${ }^{(29)}$, than the most frequently measured absolute threshold ${ }^{(15)}$. The aim of the present study was to investigate and compare, in subjects with cognitive disorders and in a healthy comparison group, the olfactory detection abilities using JNDs and to assess their potential utility as a complementary tool in the diagnosis of dementia.

\section{METHODS}

\section{Participants}

Two participant groups were recruited in this study: a group of patients (mean age $=78$ years) and a control group (mean age = 77 years 10 months). Both groups $(\mathrm{N}=15)$ were matched for age $(\mathrm{t}=0.094, n s)$, gender (i.e. 6 females and 9 males in each group) and education level. The participants of the patient group were recruited from the neurology department of an university hospital. All patients had a dementia according to the DSM-IV diagnostic criteria (Diagnostic and Statistical Manual of Mental Disorders, fourth edition). Standard criteria were used for diagnosis of a specific dementing illness. Exclusion criteria were the same for both groups, i.e. traumatic brain injury, progressive psychiatric illness, history of brain or nasal surgery, smoking, nasal congestion at the time of tests and participants did not have any disorders of comprehension instructions. Healthy volunteers of the control group were non-smokers and none of them had a nasal/sinus disease, a neurological or a psychiatric history.

\section{Neuropsychological Evaluation}

All controls and patients underwent the RAPID neuropsychological battery ${ }^{(30)}$, including the following tests: the Memory Impairment Screen (MIS) ${ }^{(31,32)}$, the Isaacs Set Test (IST) ${ }^{(32,33)}$, the Mini-Mental State Examination (MMSE) ${ }^{(34)}$, the Free and Cued Selective Recall Test (FCSRT) ${ }^{(35)}$, the Trail Making Test (TMT) forms A and B ${ }^{(36)}$, the Crossing-Off-Test (COT) ${ }^{(37)}$, a test for picture naming ${ }^{(30)}$, a test for copying geometric figures as part of the cognitive evaluation battery and a test for matching categories ${ }^{(38)}$. All these tests were normalized on a cohort of healty controls according to age and level of education ${ }^{(30)}$.

\section{Olfactory tests}

The odorant used was the butanol $\left(\mathrm{C}_{4} \mathrm{H}_{10} \mathrm{O}\right)$ (Table 1), a neutral smell with middle trigeminal properties ${ }^{(39)}$. Dilution series (factor 2) were prepared in deionized water. After successive dilutions (Table 2), the full series included steps 1 to 11 (step 1

as the highest concentration). Four $\mathrm{mL}$ of each concentration were placed in a glass tube $(7.5 \mathrm{~cm}$ high, $1 \mathrm{~cm}$ in diameter at the opening). Step 6 was used as the reference concentration. Ten concentrations (steps 1 to 5 and steps 7 to 11) were presented in a randomized order into 5 series. A total of 50 trials were performed, i.e. 5 trials for each stimulus comparison. A rest period of 1 minute was observed between the series. The full experiment lasted about 30 minutes. All concentrations were compared to the step 6 (as referent) in a classical two alternative forced-choice task. A rack with the reference tube and another tube, more or less concentrated, was presented to the subject who had to report, which one was more concentrated.

\section{JND calculations}

The JND was calculated by using the following equations commonly performed in obtaining upper and lower limits ${ }^{(40)}$.

Upper Limit

$$
\mathrm{Su}=\left(\mathrm{Cu}+\frac{\mathrm{D}}{2}\right)-\frac{\left(\sum_{\mathrm{i}=1}^{\mathrm{p}} \mathrm{Ui}\right)}{\mathrm{n}} \mathrm{D}
$$

Lower Limit

$$
\mathrm{S}_{\mathrm{L}}=\left(\mathrm{CL}+\frac{\mathrm{D}}{2}\right)+\frac{\left(\sum_{\mathrm{i}=1}^{\mathrm{p}} \mathrm{Li}\right)}{\mathrm{n}} \mathrm{D}
$$

Differential Threshold

$$
\Delta \mathrm{L}=\frac{\mathrm{SU}-\mathrm{SL}}{2}
$$

$C_{U}$ : Maximum stimulus compared, $C_{L}$ : Minimum stimulus compared, $U_{i}$ : Total number of judgments that belong to the high limit in the " $i$ " th stimulus comparison, $L_{i}$ : Total number of judgments that belong to the "low" limit in the " $i$ " th stimulus comparison, $n$ : Number of trials performed in each stimulus comparison, $D$ : Step size of comparison stimulus, $p$ : Total number of comparison stimulus. For each concentration tested, the discrimination threshold was defined as the stimulus magnitude of the comparison at which the proportion of correct responses was equal to 0.75 .

\section{Statistical analysis}

The Student t-test (independent) was used to compare the demographic, neuropsychological and olfactory variables of both patient and control groups. The Spearman's correlation coefficient was performed to study the relation between olfactory and cognitive performances. The significance threshold was set at 0.05 . The non-significant analyses were noted as ns.

\section{RESULTS}

\section{Olfactory performances}

The results are presented in Figure 1. The statistical analysis showed a significant difference between both populations (patient and control groups) for JNDs measures $[t=2.328$, $p<0.02]$ indicating higher JNDs for the patients. Additionally, when the four patients with vascular dementia were excluded from the patient group $(\mathrm{N}=11)$ the statistical difference was strongly increased $[t=3.974, p<0.0006]$. 
Table 1. Properties of butanol.

\begin{tabular}{ccccccc}
\hline Chemical & Company & CAS* & $\begin{array}{c}\text { Molecular } \\
\text { formula }\end{array}$ & $\begin{array}{c}\text { Mol } \\
\text { wt }\end{array}$ & $\begin{array}{c}\text { Density } \\
\mathrm{g}^{\prime} \mathrm{cm}^{3}\end{array}$ & $\begin{array}{c}\text { Mol } / \mathrm{cm}^{3} \\
\text { Butanol }\end{array}$ \\
\hline Sigma & $71-36-3$ & $\mathrm{C}_{4} \mathrm{H}_{10} \mathrm{O}$ & 74.12 & 0.81 & $10.9 \times 10^{-3}$ \\
\hline
\end{tabular}

* The American Chemical Society's Chemical Abstracts Service (CAS) registry number

Table 2. Concentrations of butanol obtained by successive dilutions (factor 2).

\begin{tabular}{cccc}
\hline \multirow{2}{*}{$\begin{array}{c}\text { Dilution } \\
\text { Step }\end{array}$} & $\begin{array}{c}\text { Concentration } \\
(\% \mathrm{v} / \mathrm{v})\end{array}$ & $\mathrm{g} / \mathrm{cm}^{3}$ & $\mathrm{Mol} / \mathrm{cm}^{3}$ \\
\cline { 3 - 4 } $\begin{array}{c}\text { Pure liquid } \\
2\end{array}$ & 100 & 0.81 & $10.9 \times 10^{-3}$ \\
3 & 50 & 0.405 & $5.45 \times 10^{-3}$ \\
$\ldots$ & 25 & 0.2025 & $\ldots$ \\
$\ldots$ & $\ldots$ & $1.579 \times 10^{-3}$ & $\ldots .725 \times 10^{-3}$ \\
$\ldots$ & 0.195 & $\ldots$ & $2.125 \times 10^{-5}$ \\
\hline
\end{tabular}

Table 3. Cognitive performances (Control group vs Patient group).

\begin{tabular}{|c|c|c|c|c|c|}
\hline \multirow[b]{2}{*}{ Neuropsychological tests } & \multicolumn{2}{|c|}{ Control group $(n=15)$} & \multicolumn{2}{|c|}{ Patient group $(n=15)$} & \multirow{2}{*}{$\begin{array}{c}\begin{array}{c}\text { Student-t test } \\
\text { (independent) }\end{array} \\
\mathrm{p}\end{array}$} \\
\hline & $\mathrm{m}$ & $\sigma$ & $\mathrm{m}$ & $\sigma$ & \\
\hline MIS & 7.5 & 0.7 & 4.5 & 2 & $0.0001 * * *$ \\
\hline IST & 27.66 & 1.91 & 21.33 & 7.51 & $0.003^{* *}$ \\
\hline MMSE (max. 30) & 27.7 & 1.32 & 20.6 & 4.57 & $0.0001 * * *$ \\
\hline $\mathrm{COT}$ & 114.4 & 21.33 & 120.61 & 43.49 & 0.08 \\
\hline \multicolumn{6}{|l|}{ FCSRT } \\
\hline FR (max. 48) & 18.06 & 3.49 & 5.30 & 4.38 & $0.0001 * * *$ \\
\hline TR (max. 48) & 47.33 & 0.72 & 26.61 & 9.52 & $0.0001 * * *$ \\
\hline \multicolumn{6}{|l|}{ TMT } \\
\hline Form A & 41.26 & 9.43 & 109.86 & 87.68 & $0.005^{* *}$ \\
\hline Form B & 174.06 & 31.05 & 345.71 & 115.49 & $0.0001 * * *$ \\
\hline Picture naming ( $\max .30)$ & 29.8 & 0.41 & 26.86 & 3.18 & $0.001 * *$ \\
\hline Copying geometric figures & 6 & 0 & 5.9 & 0.3 & 0.13 \\
\hline Matching categories (max. 10) & 10 & 0 & 9.46 & 0.91 & $0.03 *$ \\
\hline
\end{tabular}

MIS: Memory Impairment Screen; IST: Isaacs Set Test; MMSE: Mini Mental State Examination; COT: Crossing-Off Test; FCSRT: Free and Cued Selective Recall Test; FR: Free recall; TR: Total Recall; TMT: Trail Making Test. m: mean ; : standard deviation ; p: p-value. $\left({ }^{*} \mathrm{p}<0.05\right.$; ${ }^{* *} \mathrm{p}<0.01$; $* * * \mathrm{p}<0.0001)$.

\section{Cognitive performances}

Results are reported in Table 3. Significant differences between the patient and control groups were observed for the following tests: MIS $(p<0.0001)$, IST $(p<0.003)$, MMSE $(p<0.0001)$, free recall of the FCSRT $(p<0.0001)$, total recall of the FCSRT $(p<0.0001)$, TMT form A $(p<0.005)$, TMT form B $(p<0.0001)$, picture naming $(p<0.001)$ and test for matching categories $(p<0.03)$. Only the results obtained at both COT $(p$ $<0.08)$ and copying geometric figures $(p<0.13)$ tests did not differ significantly between both populations. Overall, it can be considered that the patient group had significantly lower cognitive performances than the control group.
Correlations between cognitive and olfactory performances The results are reported in Table 4. For the control group, the data clearly indicated that whatever the neuropsychological test, cognitive and olfactory performances were correlated, especially in the case of IST $(p<0.005)$ and COT $(p<0.001)$, expect in the case of picture naming $(p<0.07)$. In contrast, for the patient group no significant correlation was found between cognitive and olfactory performances.

\section{DISCUSSION}

The findings of the present study are in agreement with several published papers showing that several neurological diseases 
Table 4. Correlations between performance on neuropsychological tests and JNDs.

\begin{tabular}{|c|c|c|c|c|}
\hline \multirow{3}{*}{ Neuropsychological Tests } & \multirow{2}{*}{\multicolumn{2}{|c|}{ Controls $(\mathrm{n}=15)$}} & \multirow{2}{*}{\multicolumn{2}{|c|}{ Patients $(n=15)$}} \\
\hline & & & & \\
\hline & $\mathrm{r}_{\mathrm{s}}$ & $\mathrm{p}$ & $\mathrm{r}_{\mathrm{s}}$ & $\mathrm{p}$ \\
\hline MIS & 0.53 & $0.04 *$ & 0.52 & 0.07 \\
\hline IST & 0.75 & $0.005 * *$ & 0.11 & 0.39 \\
\hline MMSE (max. 30) & 0.53 & $0.04 *$ & 0.23 & 0.39 \\
\hline $\mathrm{COT}$ & 0.84 & $0.001 * *$ & 0.08 & 0.39 \\
\hline \multicolumn{5}{|l|}{ FCSRT } \\
\hline FR (max. 48) & 0.58 & $0.03 *$ & 0.52 & 0.07 \\
\hline TR (max. 48) & 0.53 & $0.049 *$ & 0.23 & 0.42 \\
\hline \multicolumn{5}{|l|}{ TMT } \\
\hline Form A & 0.58 & $0.03 *$ & 0.01 & 0.96 \\
\hline Form B & 0.68 & $0.01 *$ & 0.16 & 0.68 \\
\hline Picture naming ( $\max .30)$ & 0.48 & 0.07 & 0.12 & 0.9 \\
\hline Copying geometric figures & 0.43 & 0.09 & 0.20 & 0.26 \\
\hline Matching categories (max. 10) & 0.53 & $0.04 *$ & 0.30 & 0.26 \\
\hline
\end{tabular}

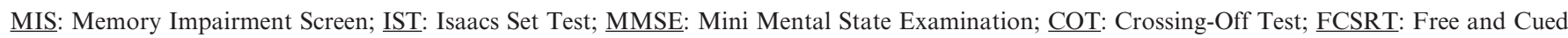
Selective Recall Test; FR: Free recall; TR: Total Recall; TMT: Trail Making Test m: mean ; $\sigma$ : standard deviation; : p-value. $\left({ }^{*} \mathrm{p}<0.05 ; * * \mathrm{p}<0.01 ; * * * \mathrm{p}<0.0001\right)$

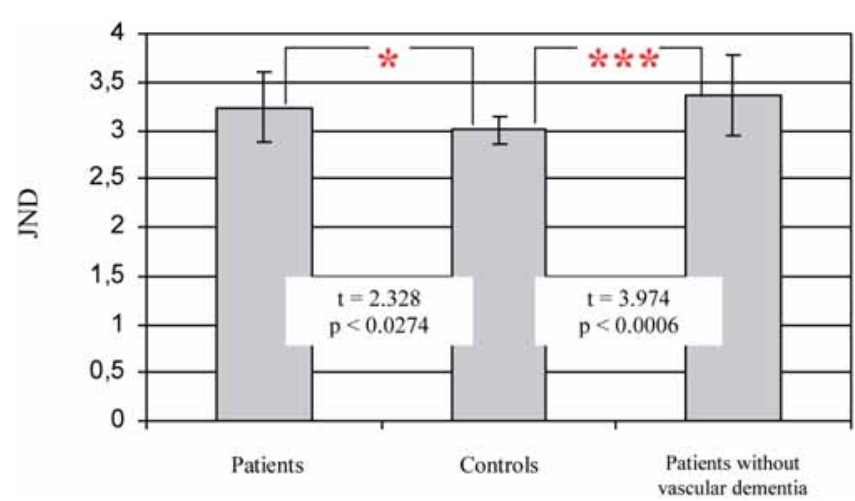

such as dementia are accompanied by olfactory disturbances. Specifically, data showed that JNDs in olfaction were significantly higher in a population with cognitive disorders associated with dementia - i.e. a lower olfactory detection performance - than in a control population paired in age. Aging itself is an important variable affecting olfaction ${ }^{(41)}$. After the age of 80 years about 70 percent of individuals have a marked impairment of olfactory functions and between 65 and 80 years, 50 percent have a quantifiable deficit ${ }^{(41,42)}$. Thus, the development of olfactory tools, which can predict dementia and discriminate between normal aging deficit and neurological pathologies are required ${ }^{(43)}$.

Additionally, the findings of the present study showed strong correlations between cognitive performances and JND scores in the control population contrary to the patient population. The strong correlation in the control group was mainly due to the small standard deviation around the mean scores for all cognitive tests showing an homogeneous population. In con-
Figure 1. Just noticeable differences (JNDs) in olfaction obtained with butanol odorant in three populations: Patients $(\mathrm{N}=15$; patients with cognitive disorders associated with dementia), Controls $(\mathrm{N}=15$; paired in sex, age and education level with the patient group,) and Patients without vascular dementia $(\mathrm{N}=11$; four participants with vascular dementia were excluded from the Patients group).

trast, the patient group presented a great standard deviation around the mean scores for several cognitive tests while the dispersion of JND scores was weak. Cognitive disturbances in the patient group depend on many factors such as disease duration, medical treatment or specific nervous central structure deterioration, which prevent a correlation between JND and cognitive scores.

Overall, these results suggested that JNDs could be an interesting tool added to classical cognitive evaluation in determining neuropsychological diagnosis in the elderly. Indeed, olfactory detection tests are relevant in the case of patients with dementia insofar as the task did not involve specific cognitive processes. Moreover, these findings are in agreement with a recent published work ${ }^{(44)}$, which suggested that the JND in olfaction could be a more discriminative tool than the classical absolute threshold.

Specifically, in normal elderly population, scores in MMSE, 
a marker widely used in cognitive neurology to characterize the overall cognitive efficiency, are correlated with JNDs. Performances in olfactory sensitivity are also highly correlated with memory performance, speed of information processing and executive function. The interest of these results focuses on the parallel evolution of memory scores and olfactory performances, i.e.when cognitive performance declines, olfactory performance declines too. This correlation was not observed in the group of patients who showed cognitive impairment associated with different types of dementia (vascular dementia, degenerative, mixed and possible or probable dementias). However, memory impairment is one of the first symptoms of most neurodegenerative diseases such as ATD ${ }^{(16)}$, and it would be interesting to incorporate into the interview with persons coming in clinical memory consultation, questions concerning the olfactory complaints, which are never expressed spontaneously. In addition, the award of olfactory tests in the neuropsychological assessment could provide valuable information on brain function of patients and could contribute to the differential diagnosis of dementia. Indeed, specific dementia such as vascular dementia ${ }^{(45)}$ could be logically not associated with olfactory sensitivity deficits and could obtain similar thresholds than those of elderly controls. As a consequence, it would be appropriate for further study, to establish a patient population including more subjects and more homogeneous characteristics at the clinical level (i.e., subgroups of patients characterized by a particular type of dementia) to study the performance in terms of olfactory JNDs in comparison with a control group.

Finally, the use of olfactory tests such as JNDs in the diagnosis of neurodegenerative diseases raises a strong interest because of their accuracy added to the non-invasive and low-cost characters of this tool.

\section{REFERENCES}

1. Naessen R. An enquiry on the morphological characteristics and possible changes with age in the olfactory region of man. Acta Otolaryngologica, 1971; 71: 49-62.

2. Liss L., Gomez F. The nature of senile changes of the human olfactory bulb and tract. Arch Otolaryngol, 1958; 67: 167-171.

3. Smith CG. Age incidence of atrophy of olfactory nerves in man: a contribution to the study of the process of aging. J Comp Neurol. 1942; 77: 589-596.

4. Norman M. Management of smell and taste problems. Cleve Clin J Med. 2002; 69: 329-336.

5. Murphy C. Age-related effects on the threshold, psychophysical function, and pleasantness of menthol. J Gerontol. 1983; 38: 217-222.

6. Doty RL, Snow JB. Age-related alterations in olfactory structure and function. In Margolis FL, Getchell TV, eds. Molecular Neurobiology of the olfactory system. Plenum Publishing Corporation, New York, 1988; 355-374.

7. Serby M, Larson PM, Kalkstein D. Olfaction and neuropsychiatry. In: Serby MJ et Chobor KL, eds. The science of olfaction, 21, Springer-Verlag, New York, 1992; 559-584.

8. Cain WS. To know with the nose; Keys to odor identification. Science, 1979; 203: 467-470.

9. Eskenazi B, Cain WS, Novelly RA, Mattson R. Odor perception in temporal lobe epilepsy patients with and without temporal lobectomy. Neuropsychologia, 1986; 24: 553-562.

10. Steven JC, Cain WS, Demarque A. Memory and identification of stimulated odors in elderly and young persons. B. Psychon. Soc., 1990; 28: 293-296.

11. Murphy C, Cain WS, Gilmore MM, Skinner RB. Sensory and semantic factors in recognition memory for odors and graphic stimuli: Elderly versus young persons. Am J Psychol. 1991; 104: 161-192.

12. Lehrner JP, Walla P, Laska M, Deecke L. Different forms of human odor memory: a developmental study. Neurosci Lett. 1999; 272: 17-20.

13. Royall DR, Chiodo LK, Polk MS, Jaramillo CJ. Severe dysosmia in specifically associated with Alzheimer-like memory deficits in no demented elderly retirees. Neuroepidemiol. 2002; 21: 68-73.

14. Gomez-Isla T, Price JL, McKeel DW, Morris JC, Growdow JH, Hyman BT. Profound loss of layer II entorhinal cortex neurons occurs in very early Alzheimer's disease. J Neurosci. 1996; 16: 4491-4500.

15. Doty RL. Handbook of olfaction and gustation. 2003. Marcel Dekker, New York.

16. McShane RH, Nagy Z, Esiri MM, King E, Joakim C, Sullivan N, Smith AD. Anosmia in dementia is associated with Lewy bodies rather than Alzheimer's pathology. J Neurol Neurosurg Psychiat. 2001; 70: 739-743.

17. Esiri MM, Wilcock GK. The olfactory bulbs in Alzheimer's disease. J Neurol Neurosurg Psych. 1984; 47: 50-60.

18. Kovacs T, Cairns NJ, Lantos PL. Olfactory centers in Alzheimer's disease: olfactory bulb is involved in early Braak's stages. Neuroport. 1999; 12: 285-288.

19. Reyes PF, Golden GT, Fagel PL, Fariello RG, Katz L, Carner E. The prepiriform cortex in dementia of the Alzheimer's type. Arch Neurol. 1987; 44: 644-645.

20. Doty RL, Reyes PF, Gregor T. Presence of odor identification and detection deficits in Alzheimer's disease. Brain Res Bull. 1987; 18: 597-600.

21. Nordin S, Murphy C. Impaired sensory and cognitive olfactory function in questionable Alzheimer's disease. Neuropsychologica, 1996; 10: 113-119.

22. Ansari K.A., Johnson A. Olfactory function in patients with Parkinson's disease. J Chron Dis. 1975; 28: 497.

23. Gilbert PE, Barr PJ, Murphy C. Differences in olfactory and visual memory in patients with pathologically confirmed Alzheimer's disease and the Lewy body variant of Alzheimer's disease. J Int Neuropsycholo Soc. 2004; 10: 835-842.

24. Koss E, Weiffenbach JM, Haxby JV, Friedland RP. Olfactory detection and identification performance are dissociated in early Alzheimer's disease. Neurology, 1988; 38: 1228-1232.

25. Serby M, Larson P, Kalkstein D. The nature and course of olfactory deficits in Alzheimer's disease. Am J Psychiat. 1991; 148: 357-360.

26. Morgan CD, Nordin S, Murphy C. Odor identification as an early marker for Alzheimer's disease: Impact of lexical functioning and detection sensitivity. J Clin Exp Neuropsychol. 1995; 17: 793-803.

27. Le Berre E, Béno N, Ishii A, Chabanet C, Etiévant P, ThomasDanguin T. Just noticeable differences in component concentrations modify the odor quality of a blending mixture. Chemical Senses, 2008; 33: 389-395.

28. Eichenbaum H, Morton TH, Potter H, Corkin C. Selective olfactory deficits in case H.M. Brain. 1983; 106: 459-472.

29. Slotnik BM, Bell GA, Panhuber H, Laing DG. Detection and discrimination of proprionic acid after removal of its 2-DG identified major focus in the olfactory bulb: a psychophysical analysis. Brain Res. 1997; 762: 89-96.

30. Ferreira S, Vanholsbeeck G, Chopard G, Pitard A, Tio G, Vandel $\mathrm{P}$, Galmiche J, Rumbach L. Comparative norms of RAPID neuropsychological battery for subjects between 50 to 89 years. Revue Neurologique, 2010; 166: 606-614.

31. Buschke H, Kuslansky G, Katz M. Screening for dementia with the memory impairment screen. Neurology. 1999; 52: 231-238.

32. Chopard G, Pitard A, Ferreira S, Vanholsbeeck G, Rumbach L, Galmiche J. Combining the memory impairment screen and the Isaacs Set Test: a practical tool for screening dementias. J Am Geriat Soc. 2007; 55: 1426-1430. 
33. Isaacs B, Kennie AT. The Set Test as an aid to the detection of dementia in old people. Br J Psych. 1973; 123: 467-470.

34. Folstein MF, Folstein SE, Mc Hugh PR. "Mini mental state": a practical method for grading the cognitive state of patients for the clinician. J Psychiat Res. 1975; 12: 189-198.

35. Grober E, Buschke H. Genuine memory deficits in dementia. Developmental Neuropsychology. 1987; 3: 13-36.

36. Reitan R. Validity of the Trail-Making Test as an indicator of organic brain damage. Percept Mot Skills. 1958; 8: 271-276.

37. Goldman WP, Baty JD, Buckles VD. Motor dysfunction in mildly demented AD individuals without extrapyramidal signs. Neurology. 1999; 53: 956-962.

38. Signoret JL, Allard M, Benoit N, Bolgert F, Bonvarlet M, Eustache F. Evaluation des troubles de mémoire et des désordres cognitifs associés. BEC 96. Paris: Ipsen, 1998.

39. Doty RL, Brugger WPE, Jurs PC, Orndorff MA, Snyder PJ, Lowry LD. Intranasal trigeminal stimulation from odorous volatiles: psychometric responses from anosmics and normal humans. Physiol Behav 1978; 20: 175-185.

40. McKee S, Klein SA, Teller DY. Statistical properties of forcedchoice psychometric functions: Implications of probit analysis. Percept Psychophys. 1985; 37: 286-298.

41. Doty RL, Shaman P, Applebaum SL, Giberson R, Siksorki L, Rosenberg L. Smell identification ability: changes with age. Science, 1984; 226:1441-1443.

42. Murphy C, Schubert CR, Cruickshanks KJ, Klein BE, Klein R, Nondahl DM. Prevalence of olfactory impairment in older adults. JAMA. 2002; 288: 2307-2312.

43. Talbert MH, Liu X, Doty RL. A 10-item smell identification scale related to risk for

44. Jacquot L, Hidalgo J, Brand G. Just noticeable difference in olfaction is related to trigeminal component of odorants. Rhinology. 2010; 48: 281-284

45. Knupfer L, Spiegel R. Differences in olfactory test performance between normal aged, Alzheimer and vascular type dementia individuals. Int J Geriat Psychiat, 1981; 1: 3-14.

Dr Gerard Brand

Neuroscience Lab

Université de Franche

Besançon

France

E-mail: gerard.brand@univ-fcomte.fr

\section{ADVERTISEMENT}

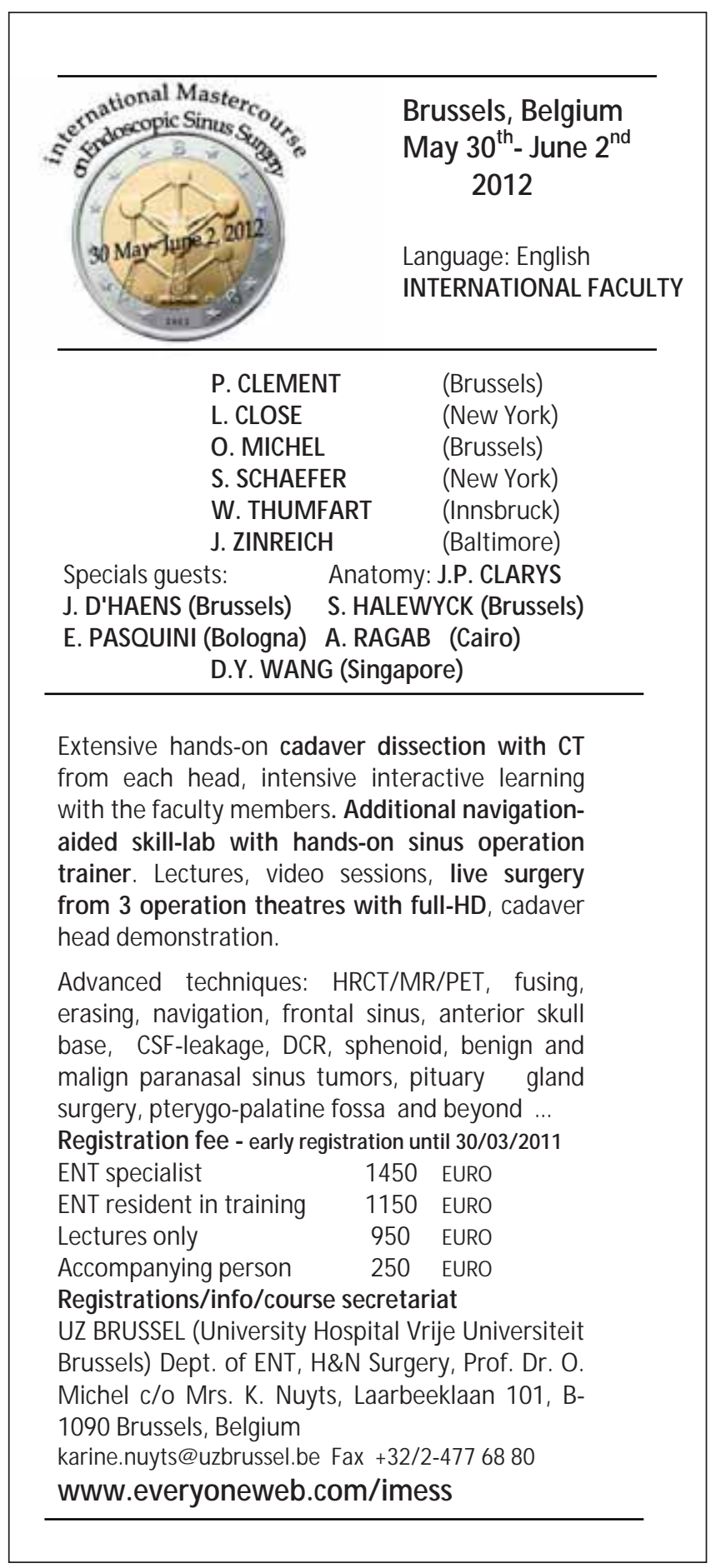

